\title{
Entre "o já-dito e o a-se-dizer": \\ o Programa de Pós-Graduação em Ciências das Linguagem
}

\author{
Between "what was said and what is to be said": The post graduation program \\ in language science
}

Débora Massmann ${ }^{1}$

Universidade do Vale do Sapucaí

\begin{abstract}
- RESUMO: Neste artigo, buscamos historicizar o trabalho pioneiro desenvolvido por Eni P. Orlandi no sul de Minas Gerais através da idealização de um projeto inédito para aquela região: a instalação de um Programa de Pós-Graduação em Ciências da Linguagem (Mestrado e Doutorado). Tomamos, pois, o percurso intelectual da pesquisadora como um objeto de reflexão para compreendermos o trabalho de Orlandi (e os sentidos que daí derivam) na institucionalização e consolidação deste projeto inovador não só para a Universidade do Vale Sapucaí (UNIVÁS), mas também para a região Sul do Estado de Minas Gerais.
\end{abstract}

- PALAVRAS-CHAVE: Linguagem. Sociedade. Análise de Discurso.

- ABSTRACT: In this paper we intend to historicize the previous work developed by Eni P. Orlandi in the South of Minas Gerais state through the idealization of a unique project developed for that region: the implementation of a Post-Graduation Program in Language Science (master and Doctor Degrees). So, in attention to the intellectual career of this researcher as a way of reflection that can lead us to the understanding to Orlandi's production (and the meanings that derivate from it) is the institutionalization and consolidation of this innovative project, not only to Vale do Sapucaí University (UNIVÁS), but also to the South of Minas Gerais State.

- KEYWORDS: Language. Society. Discourse Analysis.

Para alguns, o já-dito é fechamento de mundo.

Porque estabelece, delimita, imobiliza.

No entanto, também se pode pensar que aquilo que se diz,

uma vez dito, vira coisa no mundo: ganha espessura, faz história.

(ORLANDI, 1983)

A epígrafe selecionada para esta reflexão já nos inquieta e nos surpreende por sua força teórica e por sua delicadeza poética. É assim que compreendemos a produção intelectual e a obra de Eni P. Orlandi que, ao longo das últimas décadas, possibilitou aos estudiosos da linguagem ir além das fronteiras epistemológicas da linguística e permitiu que novos diálogos científicos fossem realizados à medida que trouxe novas questões e novas problemáticas para o estudo da linguagem na sua relação com o social. Se para alguns o já-dito é fechamento, conclusão, trava e fim, para Eni P. Orlandi, o já-dito é/está no/do mundo, é possibilidade de circulação, (re)formulação, (re)significação,

\footnotetext{
${ }^{1}$ Doutora em Letras pela USP. Docente do Programa de Pós-Graduação em Ciências da Linguagem (PPGCL) - Universidade do Vale do Sapucaí (UNIVÁS) debora.massmann@univas.edu.br
} 
produção, repetição, interpretação. É linguagem em funcionamento na sociedade que se manifesta sob forma de tensão entre aquilo que é dinâmico, isto é, o que muda e se transforma, e aquilo que perdura, ou seja, o que continua e insiste em permanecer. É essa tensão, segundo Orlandi (1983, p. 7), "entre o retorno e o avanço, entre o que restringe e o que alarga, entre o que já é e o que pode ser, entre o mesmo e o diferente" que lhe motiva a refletir sobre a relação que se estabelece entre o simbólico e o político, entre "o já-dito e o a-se-dizer" (ORLANDI, 1983, p. 7).

Considerada entre as grandes intelectuais brasileiras, Eni P. Orlandi trouxe contribuições revolucionárias e absolutamente pertinentes para a área de Letras e Linguística à medida que se interessou por um objeto de estudo inovador - o discurso com vistas a compreender os laços entre linguagem, sujeito, sociedade e história. Como a própria autora descreve,

\begin{abstract}
se o objeto de estudo (...) é de caráter múltiplo e indeterminado, o objetivo, entretanto, é sempre um: incorporar as noções de social e de história, distinguir o estabelecido e o não-estabelecido e questionar a consciência (...) dessa distinção no homem, quando este produz linguagem. Como a área em que se inserem esses estudos é a da Análise de Discurso, não poderia prescindir do compromisso com o fragmentário, o múltiplo, o provisório (ORLANDI, 1983, p. 8) .
\end{abstract}

Nas palavras de Orlandi, descortina-se o desenvolvimento de um projeto intelectual para um campo de saber que, nesta época (1970, 1980), no Brasil, dava seus primeiros passos: a Análise de Discurso. Neste preâmbulo, objeto de estudo, objetivos e teoria são descritos e apresentados para aqueles pesquisadores que já nos anos 70 e 80 tinham sensibilidade, sagacidade e perspicácia para se debruçar sobre o desafio de analisar e compreender, para além da linguística purista, a linguagem funcionando na sociedade. E, sobretudo, a relação da linguagem com a ideologia. Retornando, mais uma vez, à epígrafe desta reflexão, agora já num gesto analítico que se manifesta pelo recorte de "aquilo que se diz, uma vez dito, vira coisa no mundo: ganha espessura, faz história", somos levados a compreender e a metaforizar que, ao dizer ${ }^{3}$ sobre as especificidades da Análise de Discurso, a teoria virou coisa no mundo: ganhou espessura e fez história.

De fato, hoje, a Análise de Discurso está consolidada como um dos principais domínios de investigação das Ciências da Linguagem, não só no Brasil, mas também fora dele. Por aqui, grande parte dessa consolidação deve-se ao trabalho incansável de Eni P. Orlandi, em primeira instância, no desenvolvimento, formulação e circulação do dispositivo teórico-analítico da Análise de Discurso através de seus escritos; e, em segunda instância, pelo seu comprometimento com a formação de qualidade de um grande número de pesquisadores distribuídos em diferentes instituições brasileiras, de várias regiões do Brasil.

Considerando o percurso traçado por Eni P. Orlandi no domínio das Ciências da Linguagem e, sobretudo, a genialidade, a produtividade e o impacto científico-social de sua obra, render homenagem à autora é, pois, se inscrever em um espaço em que se entrelaçam trajetórias pessoais e profissionais que têm (n)o discurso como ponto de encontro (de partida e de chegada) e de formação para novas escutas, formas de ser, de estar e de perceber a linguagem, o sujeito, a sociedade e a história. As homenagens à

\footnotetext{
${ }^{2}$ Recorte retirado do texto de Apresentação da primeira edição da obra "A linguagem e seu funcionamento. As formas do discurso", publicada em 1983.

3 A obra "A linguagem e seu funcionamento. As formas do discurso" é o primeiro livro publicado por Eni P. Orlandi (1983). Antes disso, a autora já havia escrito diversos artigos, conferências e ensaios, entre outros textos acadêmicocientíficos, em que tratou de questões relativas à teoria e análise do discurso.
} 
Eni P. Orlandi e à produtividade de seu trabalho se materializam sob diferentes formas: depoimento, vídeo, poema, livro, congresso, artigo científico, ensaio, espetáculo de dança, exposição fotográfica, instalação artística, entrevista, etc. Possivelmente, os modos de dizer e de significar essas homenagens à autora são tão diversos quanto os temas sobre os quais ela tem se debruçado ao longo de sua produção intelectual. Essa diversidade de saudações e de agradecimentos à pesquisadora aponta, com efeito, para a relevância de sua obra, mas também significa sobre os afetos que atravessam as relações profissionais e pessoais da pesquisadora, da professora, da coordenadora, da orientadora, da amiga Eni P. Orlandi.

De nossa parte, a homenagem aqui exposta se funda na especificidade do trabalho, mais uma vez, pioneiro, desenvolvido por Eni P. Orlandi no sul de Minas Gerais através da idealização de um projeto inédito para aquela região, a saber, a instalação de um Programa de Pós-Graduação em Ciências da Linguagem (Mestrado e Doutorado). Tomamos, pois, o trabalho intelectual como um objeto de reflexão, uma vez que ele materializa o real de nosso percurso na história, sobretudo, aquele nas/das instituições. Nosso objetivo é, pois, refletir sobre o trabalho de Orlandi (e os sentidos que daí derivam) na institucionalização e consolidação deste projeto inovador não só para a Universidade do Vale Sapucaí (UNIVÁS), mas também para a região Sul do Estado de Minas Gerais.

\section{Condições de produção: a força do ferreiro e habilidade da língua}

Historicizar o trabalho desenvolvido por Eni P. Orlandi na Universidade do Vale do Sapucaí (UNIVÁS), em Pouso Alegre (Minas Gerais), é, de certa forma, contribuir para o registro de uma etapa importante e recente da História das Ideias Linguísticas no Brasil. Isso porque o objetivo dessa reflexão é dar a conhecer o papel decisivo de Orlandi no desenvolvimento de um projeto acadêmico-intelectual, de longo prazo, que visava a ampliação das modalidades de ensino para além da graduação e, sobretudo, a instalação da pesquisa na UNIVÁS. Buscava-se assim fomentar o tripé - ensino, pesquisa e extensão - fundamental na produção e circulação do conhecimento nas instituições de ensino superior e, ainda, dar condições para que o conhecimento ali produzido pudesse ter sua visibilidade ampliada para além das fronteiras do sul de Minas.

Assim, em 2002, Orlandi é convidada a instalar o primeiro curso de Mestrado da Universidade do Vale do Sapucaí. O convite, realizado por uma professora da UNIVÁS, à época aluna de um dos cursos que a professora Eni P. Orlandi ministrava no Instituto de Estudos da

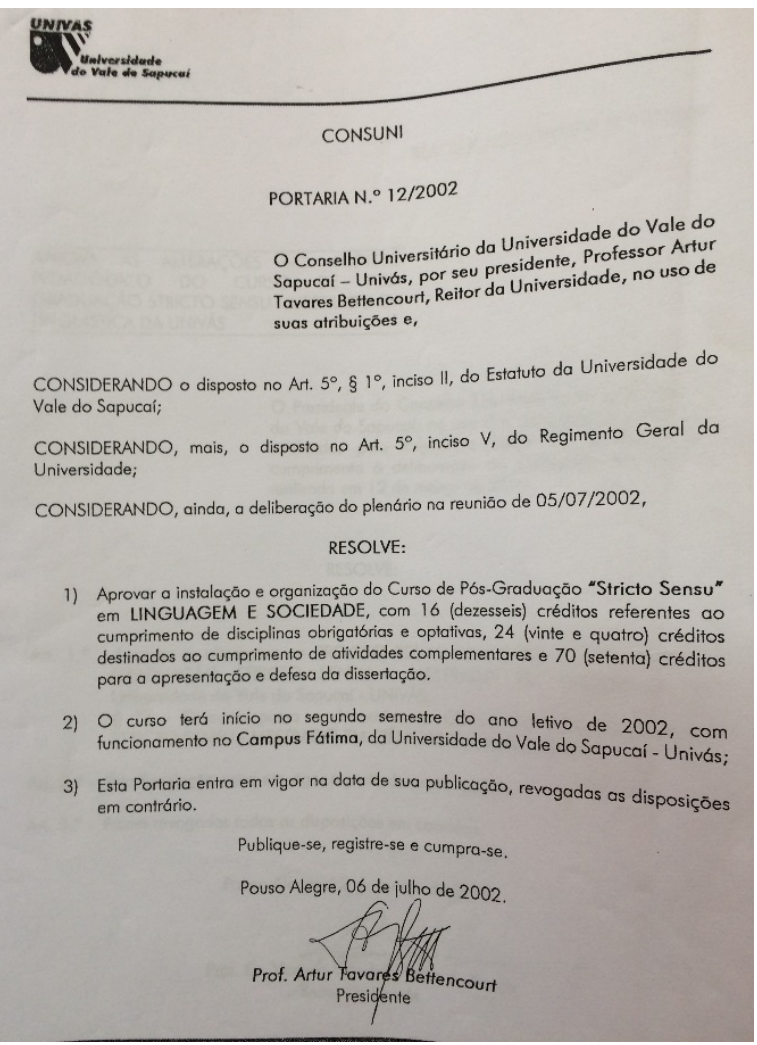
Linguagem (IEL) da Universidade Estadual de Campinas (UNICAMP), se deu, sobretudo, em função do modo como a Análise de Discurso sempre reuniu pesquisadores de diferentes áreas do conhecimento em torno de um mesmo objeto, a 
linguagem. Conforme destaca Orlandi $\left(2017^{4}\right)$, a ideia era elaborar uma proposta de curso que tivesse escopo na relação linguagem e sociedade já que aquela sempre ocupou um lugar nucleador e mediador das relações entre o homem com seu entorno. Assim, a proposta encampada pela UNIVÁS de instalar um mestrado na área de Linguagem se apresentou como pioneira já que se constituiu, a partir das orientações de Orlandi, tomando como ponto de partida o pressuposto de que a linguagem deveria ser pensada na sua relação com o social. Relação esta que não estava sustentada na simples articulação de uma exterioridade ao funcionamento linguístico, mas sim na compreensão de que a exterioridade é constitutiva dos processos de produção de sentido, isto é, da linguagem funcionando na sociedade. Buscava-se assim construir na UNIVÁS um espaço de produção de conhecimento e de qualificação profissional em nível de pós-graduação para um público alvo oriundo de diferentes domínios científicos. Desse modo, no dia 06 de julho de 2002, o Conselho Universitário da UNIVÁS, à época sob a presidência do Magnífico Reitor, Prof. Artur Tavares Bittencourt, aprovou a instalação e a organização do "Mestrado em Linguagem e Sociedade" que deveria iniciar suas atividades, em caráter imediato, já no segundo semestre do corrente ano.

A abertura ${ }^{5}$ observada, já em 2002, na proposta inicial do curso de Mestrado que passou a se chamar "Linguagem e Sociedade", levou em consideração a premissa de que a relação entre linguagem e sociedade é o pilar de sustentação não só para a produção (elaboração) e a circulação de diferentes formas de conhecimento como também para a formação de pesquisadores que atuam em domínios disciplinares diversos: afinal, a linguagem pode ser descrita como o "instrumento, a ferramenta de trabalho" para as mais diferentes atividades profissionais. Em outras palavras, ao colocar a relação entre linguagem e sociedade como eixo nucleador de um curso de pósgraduação stricto sensu, Orlandi promoveu efetivamente a multidisciplinaridade - multi porque justamente articulou muitas áreas do conhecimento em torno de sua proposta (re)inventando assim a relação linguagem, sujeito, ciência e história.

Nessa perspectiva, considera-se que a instalação do curso de Mestrado "Linguagem e Sociedade", conforme o projeto idealizado e coordenado por Eni P. Orlandi pode ser descrita como um acontecimento discursivo para a instituição e para a região, pois trouxe consigo novas formas de significar o ensino, a pesquisa e a extensão. Ou seja, através do trabalho ímpar de Eni P. Orlandi na fundação do curso instauram-se na UNIVÁS novas discursividades em torno dos sentidos de ciência e, pouco a pouco, as fronteiras acadêmicas do sul de Minas foram sendo alteradas.

Ainda em 2002, com o curso já em funcionamento atendendo a mais de 30 mestrandos, alguns gestos acadêmico-científicos foram marcantes no processo de institucionalização da estrutura de pesquisa para o desenvolvimento dos projetos de docentes e discentes. Um exemplo disso é a criação do Núcleo de Pesquisa em Linguagem (NUPEL), órgão vinculado ao curso, que se constituiu, desde sua gênese, como um espaço de idealização, organização, execução e gestão de projetos de pesquisas (individuais ou coletivos), grupos de estudos, grupos de pesquisas, encontros acadêmico-científicos, seminários e jornadas, entre outros. Ao idealizar o NUPEL, Orlandi criou as condições infraestruturais necessárias para a circulação e divulgação dos trabalhos desenvolvidos no âmbito do curso de mestrado. Concebido para ser um espaço aberto e dinâmico, tanto para receber pessoas interessadas nas questões de pesquisas ali desenvolvidas, quanto para articular a relação dos pesquisadores do curso com outras instituições, este núcleo de pesquisa cumpriu (e ainda cumpre) sua função

\footnotetext{
${ }^{4}$ Entrevista com Eni P. Orlandi para o curta-metragem (no prelo) "Programa de Pós-Graduação em Ciências da Linguagem (PPGCL) 15 anos".

${ }^{5}$ Característica presente até hoje no Programa de Pós-Graduação em Ciências da Linguagem (PPGCL).
} 
primeira que é aquela de manter em contato não só os alunos e professores do curso como também fazer a ligação destes com outras Instituições de Ensino Superior (IES) da região do sul de Minas, do Brasil e do exterior através da promoção e organização de diversas atividades acadêmico-científicas e culturais.

De fato, já em 2002, ano de sua criação, o Mestrado em "Linguagem e Sociedade", através do NUPEL, deu ampla visibilidade para a Universidade e também para a região à medida que organizou os primeiros eventos científicos: no mês de setembro de 2002, realizou-se a I Jornada Internacional de Linguagem que contou com a participação de duas importantes pesquisadoras francesas, a saber, Profa. Dra. Francine Mazière (Universidade de Paris XIII) e Profa. Dra. Simone Delesalle (Universidade de Paris VIII); e, em dezembro de 2002, promoveu-se o Seminário "Cidade, Escrita e Ciências" que reuniu na UNIVÁS pesquisadores de reconhecimento nacional e internacional que atuavam na Universidade Estadual de Campinas (Prof. Dr. Eduardo Guimarães e Profa. Dra. Claudia Castellanos Pfeiffer), além, de professores que já compunham o quadro docente do curso, a saber, Profa. Dra. Maria Onice Payer e Profa. Dra. Eni Orlandi.

É, pois, através de atividades como essas, realizadas tanto no âmbito da instituição, quanto fora dela, que a Universidade do Vale do Sapucaí e o curso de Mestrado começam a ser projetados geograficamente e dão os primeiros passos em direção ao desenvolvimento da produção científica e intelectual, proposta pela relação da linguagem com a sociedade, naquela região. Em outras palavras, é o trabalho de Eni P. Orlandi, seja no curso, seja fora dele ${ }^{6}$, que foi construindo na UNIVÁS um lugar de referência para os estudos em Ciências da Linguagem. A exemplo destes dois eventos iniciais, nos anos subsequentes, com o curso em funcionamento, novos espaços de diálogo científico foram propostos reunindo pesquisadores de relevância nacional e internacional que contribuíram fortemente para reforçar o trabalho que vinha sendo desenvolvido por Orlandi e sua equipe na UNIVÁS.

Nessa historicização, certamente, muitas questões mereciam um olhar analítico mais profundo e detalhado. Entretanto, o percurso que estamos desenvolvendo aqui é apenas um dos recortes possíveis sobre o modo como o trabalho de Eni P. Orlandi no sul de Minas Gerais provocou e produziu novos sentidos não só para universidade (e o que ela passou a significar) como também para seu entorno (para Pouso Alegre e região que começava a aparecer no mapa dos eventos científicos da área de Letras e Linguística). Sobre isso, é interessante observarmos, por exemplo, as temáticas que foram abordadas nas diferentes atividades promovidas pelo NUPEL entre os anos de 2002 e 20097. Tal como a proposta político-pedagógica do Mestrado, os temas selecionados para os debates acadêmicos tratavam das questões de linguagem a partir de suas condições de produção, de seus modos de ser/estar no mundo. Em outras palavras, percorrendo a lista de eventos, podemos verificar que todos eles tratavam de linguagem... a linguagem tomada como processo de significação funcionando na sociedade e na história, conforme se pode observar na tabela ${ }^{8}$ aqui abaixo:

2002 I Jornada Internacional de Linguagem

Cidade, Escrita e Ciências

2003 Linguagem e sociedade contemporânea

\footnotetext{
${ }^{6}$ Através da participação da Profa. Eni P. Orlandi em diferentes congressos científicos, nacionais e internacionais.

${ }^{7}$ Neste período, o curso de mestrado funcionava sob a supervisão e autenticação do Conselho Estadual de Educação do Estado de Minas Gerais.

8 PROGRAMA DE PÓS-GRADUAÇÃO EM CIÊNCIAS DA LINGUAGEM. Arquivo do PPGCL. In PRÓREITORIA DE PESQUISA E PÓS-GRADUAÇÃO. Arquivo Institucional. Universidade do Vale do Sapucaí. Pouso Alegre, 2002-2009.
} 
Discurso e Corpo

Linguagem não verbal: Cinema e Fotografia

Pensar o corpo

2004 Mattoso Câmara Júnior: Linguista brasileiro

Corpos da (na) dança - subjetividades constituídas no discurso corporal

2005 Seminários temáticos sobre as pesquisas realizadas por discentes do curso

2006 Seminários temáticos sobre as pesquisas realizadas por discentes do curso

2007 I Encontro de Estudos da Linguagem (ENELIN) - "A língua e a sociedade moderna"

2008 II Encontro de Estudos da Linguagem (ENELIN) - Linguagem, memória e sociedade contemporânea

2009 III Encontro de Estudos da Linguagem (ENELIN)

II Encontro Internacional de Estudos da Linguagem (ENELIN)

Seminários temáticos sobre as pesquisas realizadas por discentes do curso

A regularidade das atividades de divulgação das pesquisas sempre foi (e continua sendo) um aspecto importante no desenvolvimento dos trabalhos coordenados por Eni P. Orlandi. Como destaca a autora, para formarmos um pesquisador, "é fundamental darmos condições para que ele possa (con)viver (com) a intelectualidade".

Cabe destacar aqui que, neste período (2002-2009), o curso de mestrado era mantido com a caução do Conselho Estadual de Educação de Minas Gerais, órgão que regulamentava e homologava todas as atividades desenvolvidas por docentes e discentes. Conforme destaca Orlandi $(2017)^{10}$, esse período foi importante, sobretudo, para a instituição, no processo de preparação e de elaboração do projeto político pedagógico do curso que, em 2009, foi enviado para o credenciamento na Coordenação de Aperfeiçoamento de Pessoal de Ensino Superior (CAPES).

Deve-se ressaltar ainda que, em 2009, a realização de algumas ações coadunou com a homologação do processo $^{11}$ de institucionalização do curso de mestrado e, de certa forma, essas ações já faziam anunciar novos tempos para a pós-graduação da UNIVÁS. Nesse sentido, é importante destacar dois acontecimentos de cunho acadêmico-administrativo que marcaram esse período, que vamos chamar de período de transição:

\footnotetext{
${ }^{9}$ Anotação de conversa informal.

10 Entrevista com Eni P. Orlandi para o curta-metragem (no prelo) "Programa de Pós-Graduação em Ciências da Linguagem (PPGCL) 15 anos.

${ }^{11}$ Processo este que, como destacado acima, vinha sendo realizado desde 2002.
} 
1) As alterações que foram aprovadas pelo Conselho Universitário da UNIVÁS, presidido pelo Magnífico Reitor Prof. Dr. Virgínio Cândido Tosta de Souza, em 12 de março de 2009, conforme a Resolução n.9/200912. De acordo com o referido documento, o Projeto Político Pedagógico do curso de PósGraduação stricto sensu foi alterado e, a partir da referida data, o curso passou a se chamar "Mestrado em Linguística". A nova designação, "Mestrado em Linguística", trazia traços de um processo de institucionalização que já ultrapassava os muros da UNIVÁS. Ao propor a nova nomenclatura ao curso de Mestrado, Eni P. Orlandi olhava para além da UNIVÁS, para além do Conselho Estadual de

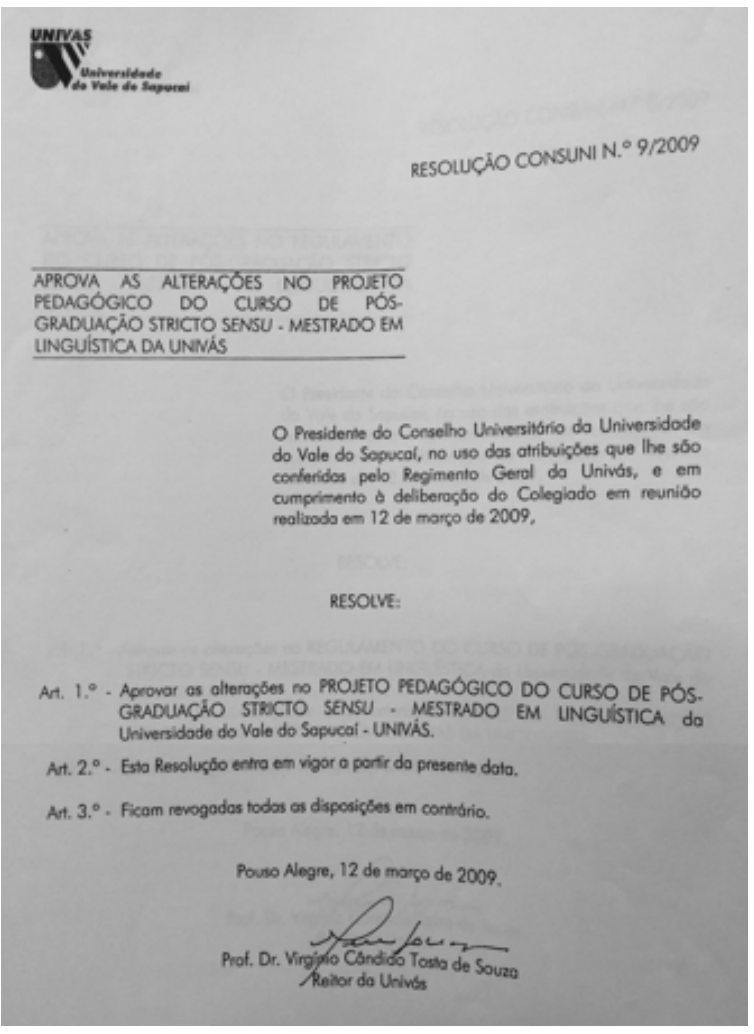
Educação. Ela já estava alinhando o curso e seu projeto político pedagógico aos requisitos da CAPES: o Mestrado em Linguística poderia assim ser inscrito à área de concentração: Linguagem e Sociedade. Esse gesto nos permite observar que a relação linguagem e sociedade continuavam ali sendo significada e funcionando como alicerce às pesquisas desenvolvidas no curso.

${ }^{12}$ CONSELHO UNIVERSITÁRIO (CONSUNI). Resolução n. 9/2009. In PRÓ-REITORIA DE PESQUISA E PÓSGRADUAÇÃO. Arquivo Institucional. Universidade do Vale do Sapucaí. Pouso Alegre, 2009. 
2) A organização, através do NUPEL, de um evento de grande proporção que contou com financiamento da Fundação de Amparo à Pesquisa do Estado de Minas Gerais (FAPEMIG). A proposta desta reunião acadêmico-científica fazia uma aglutinação entre dois eventos anteriores, a saber, o Encontro de Estudos da Linguagem (ENELIN), realizado em 2007 e 2008, e a Jornada Internacional de Linguagem, proposta em 2002. Em sua programação geral ${ }^{13}$, o evento contou com duas Conferências Internacionais (Prof. Dr. Jean-Marie Fournier (Université Paris III - França), Patrick Sériot (Université de Lausanne - Suiça), com mesasredondas - compostas por pesquisadores nacionais que

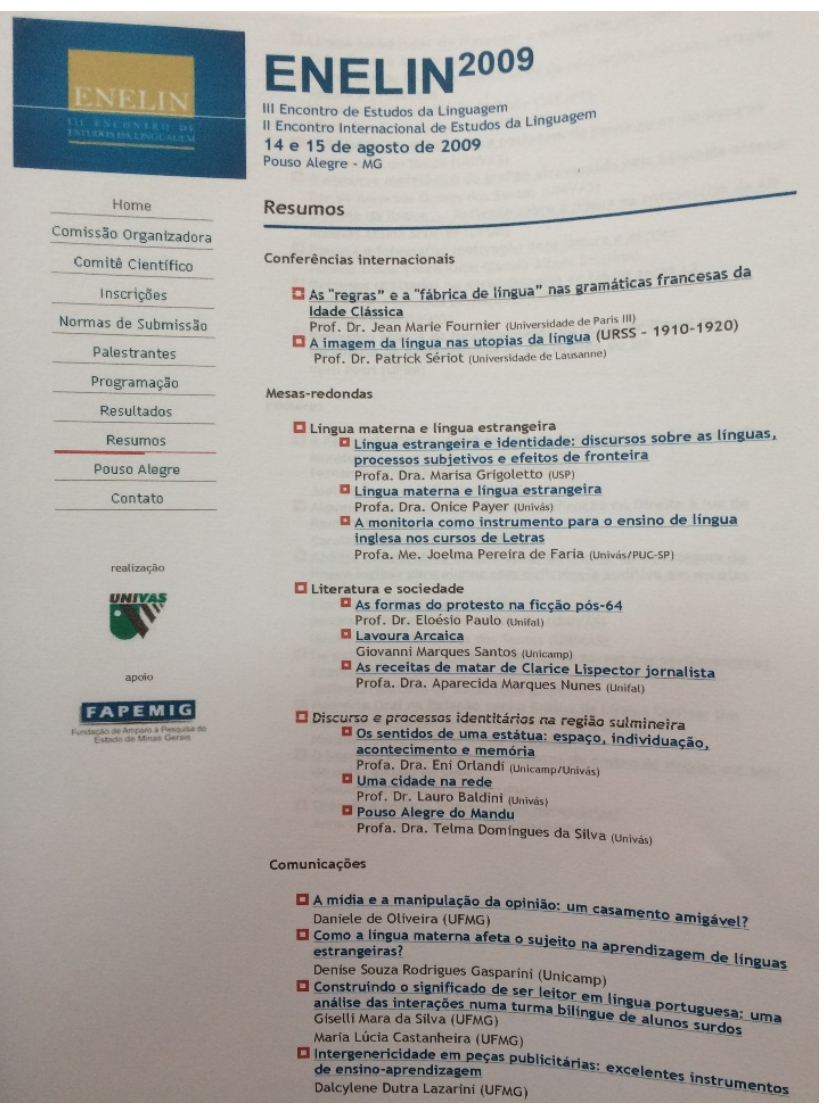
trataram das seguintes temáticas:

Língua Materna e Língua Estrangeria, Literatura e Sociedade, Discurso e processos identitários região sulmineiro -, sessão de comunicações e pôsteres. Inaugurava-se assim a estrutura de base do ENELIN tal como o conhecemos hoje.

Tomamos, pois, esses dois acontecimentos como exemplificação dessa transição no curso de Mestrado em Linguística da UNIVÁS. Chamamos o ano de 2009 de período de transição, pois, esse é o momento em que Eni P. Orlandi se dedicou à escrita do projeto político pedagógico que foi submetido à CAPES. No projeto enviado à CAPES, é possível observarmos que a área de concentração (Linguagem e Sociedade) foi mantida, entretanto, a designação do curso foi novamente alterada: de fato, o projeto recebeu o nome de "Mestrado em Ciências da Linguagem". Observa-se novamente grande abertura teórica, analítica e metodológica à proposta aprovada, credenciada e recomendada, conforme Ofício $\mathrm{N}^{\mathrm{o}} 111-20 / 2009$, em conformidade com a Portaria MEC de 18/08/2010, publicada no Diário Oficial da União de 19/8/2010, Seção 1, Pág.10.

Assim, em 2010, o Mestrado em Ciências da Linguagem iniciou suas atividades acadêmicas, credenciado e reconhecido, com nota 3, pela CAPES. Mais uma vez, o comprometimento de Eni P. Orlandi com o trabalho de pesquisa de qualidade e excelência trouxe resultados significativos para a instituição e para a região. Dizemos isso porque, em 2010, a UNIVÁS se viu diante da necessidade de se adequar às novas exigências do Ministério da Educação para as instituições de ensino superior, mais especificamente, aquelas que regulamentavam as universidades. De fato, o Conselho

\footnotetext{
13 PROGRAMA DE PÓS-GRADUAÇÃO EM CIÊNCIAS DA LINGUAGEM. ENELIN 2009. In PRÓ-REITORIA DE PESQUISA E PÓS-GRADUAÇÃ̂. Arquivo Institucional. Universidade do Vale do Sapucaí. Pouso Alegre, 2009.
} 
Nacional de Educação ${ }^{14}$ (CNE) havia lançado um conjunto de regras relativas à manutenção do status de universidade: dentre outras exigências, as instituições que tivessem um Plano de Desenvolvimento Institucional (PDI) para a instalação de cursos de pós-graduação stricto sensu reconhecido pela CAPES conseguiriam manter tal status. Neste aspecto, o novo curso, o Mestrado em Ciências da Linguagem, credenciado pela CAPES, já materializava o investimento que vinha sendo feito pela UNIVAS na implementação da pós-graduação. Os efeitos desse reconhecimento foram imediatos: de um lado, os mestrandos remanescentes foram acolhidos nesta nova configuração do curso e titulados com o reconhecimento da CAPES; de outro lado, a instituição ampliava sua visibilidade e sua posição nucleadora na região uma vez que mantinha seu status de universidade atendendo aos requisitos previstos para o período de transição à nova regulamentação do CNE.

Assim, dando continuidade ao trabalho precursor na pós-graduação da UNIVÁS, no primeiro triênio do Mestrado em Ciências da Linguagem, período de 2010 a 2013, as atividades desenvolvidas por Eni P. Orlandi na coordenação de sua equipe foram direcionadas ao investimento de qualificação do quadro docente (incentivos para pós-doutoramentos, publicações, novas contratações, etc.) e também ao processo de institucionalização da infraestrutura acadêmico-científica. Efetivamente, houve um aumento considerável nas demandas organizadas e coordenadas pelo Nupel e, a partir daí, diferentes ações foram desenvolvidas, sempre sob a orientação de Eni P. Orlandi que, com seu olhar vanguardista, soube acolher e dar condições para que fossem criados importantes instrumentos institucionais. Instrumentos estes que, hoje, como se observa aqui abaixo, constituem efetivamente parte fundamental do Programa de Pós-Graduação em Ciências da Linguagem ${ }^{15}$ :

- Revista entremeios - a revista de estudos do discurso (ISSN 2179-3514), disponível em <www.entremeios.inf.br>, é uma publicação semestral online do Programa de Pós-Graduação Ciências da Linguagem (lançada em julho de 2010).

- Seminário Integrado de Monografias, Dissertações e Teses (SIMDT) - é um evento aberto para a comunidade acadêmica da UNIVÁS, bem como para outras IES, que reúne trabalhos de iniciação científica, dissertações de mestrado e teses de doutorado (criado em 2010).

- Encontro de Estudos da Linguagem (ENELIN) - realizado desde 2007, o ENELIN é atualmente o maior evento promovido pelo PPGCL. A partir de 2009, o Encontro foi reconfigurado e passou a ter periodicidade bianual. Consolidado nacionalmente como um espaço de diálogo e de reflexão sobre os diferentes fenômenos da linguagem, o ENELIN tem, a cada nova edição, fortalecido laços interinstitucionais e reunido na UNIVÁS pesquisadores de diferentes IES do país que buscam divulgar ali pesquisas desenvolvidas sob diferentes perspectivas das Ciências da Linguagem. O evento promove Sessões Coordenadas, Comunicações Individuais, Apresentação de Pôsteres, Lançamentos de Livros e Atividades de Arte e Cultura, entre outras (criado em 2007, reconfigurado em 2009).

\footnotetext{
14 Confira < http://portal.mec.gov.br/component/content/article?id=15924:exigencia-de-doutorados-torna-maisrigidas-regras-para-as-universidades $>$. Acesso em 02 set.2017.

15 PROGRAMA DE PÓS-GRADUAÇÃO EM CIÊNCIAS DA LINGUAGEM. Arquivo do PPGCL. In PRÓREITORIA DE PESQUISA E PÓS-GRADUAÇÃO. Arquivo Institucional. Universidade do Vale do Sapucaí. Pouso Alegre, 2009-2014.
} 
- Seminário de Pesquisas em Andamento (SEPA) - é um evento de divulgação de pesquisas de mestrado, doutorado e pós-doutorado que visa apresentar e divulgar as pesquisas ainda em desenvolvimento no PPGCL (criado em 2012).

- Coleção Linguagem e Sociedade - apresentando-se como um espaço de publicação de obras científicas - livros autorais ou organizações resultado de projetos de pesquisa e convênios -, a coleção Linguagem e Sociedade busca fortalecer e fazer circular à produção científica das ciências da linguagem e de domínios disciplinares correlatos à área de concentração na qual o PPGCL se inscreve (criada em 2012).

- Centro de Documentação Denise Maldidier (CEDDEM) - organizado em parceira e com o apoio da biblioteca da UNIVÁS, o CEDDEM apresenta-se como um espaço que reúne referenciais bibliográficos e de corpus sobre os estudos em ciências da linguagem. O nome do centro é uma referência e uma homenagem à pesquisadora Denise Maldidier (criado em 2012).

- Revista DisSoL (Discurso, Sociedade e Linguagem) (ISSN: 2359-2192) - é uma publicação online, disponível em <revistadissol.univas.edu.br>, organizada, editada e dirigida pelos alunos do PPGCL da UNIVÁS. A DisSoL constitui uma ferramenta importante na divulgação da produção acadêmica das pesquisas em linguagem, sobretudo, porque se apresenta como um espaço destinado à divulgação da produção discente (de graduação e pós-graduação) (idealizada em 2013 e implementada em 2014).

- Café com Saber - é um programa cultural criado com o objetivo de levar ao público externo à UNIVÁS discussões que versam sobre temas relativos à Linguagem e Sociedade e que deem visibilidade às pesquisas que são realizadas no âmbito do PPGCL (criado em 2013).

- Centro de Ensino de Línguas (CELi) - desde 2011, o PPGCL vinha oferecendo cursos de leitura acadêmica em língua estrangeira (inglês e francês) sob forma de um projeto de extensão inéditos na região. Com o aumento da demanda, em 2015, oficialmente, inaugura-se o Centro de Ensino de Línguas (CELi) que passou a oferecer diferentes opções de cursos em língua estrangeira, sobretudo, em inglês, francês e espanhol (idealizado em 2011, oficializando em 2015). 
Todas essas ações empreendidas em 2012 podem ser descritas como parte da fundação de um projeto ainda maior: estamos nos referindo aqui ao Projeto de PósGraduação em Ciências da Linguagem, isto é, de manutenção e consolidação do mestrado e de instalação de um curso de doutorado na UNIVÁS. Assim, antes do fechamento do primeiro triênio (2010, 2011 e 2012) do curso de Mestrado, o projeto de criação do Doutorado já havia sido elaborado por Eni P. Orlandi e sua equipe e aprovado pelo Conselho Universitário da UNIVÁS, à época, sob a presidência do Magnífico Reitor Prof. Dr. Félix Carlos Ocariz Bazzano, conforme Resolução ${ }^{16}$ n.2/2012. Mais uma vez, tratava-se de um projeto pioneiro que vinha reforçar a relação linguagem e sociedade e atender à demanda da região $\mathrm{Sul}$ de Minas Gerais. De acordo com a Proposta apresenta à CAPES,

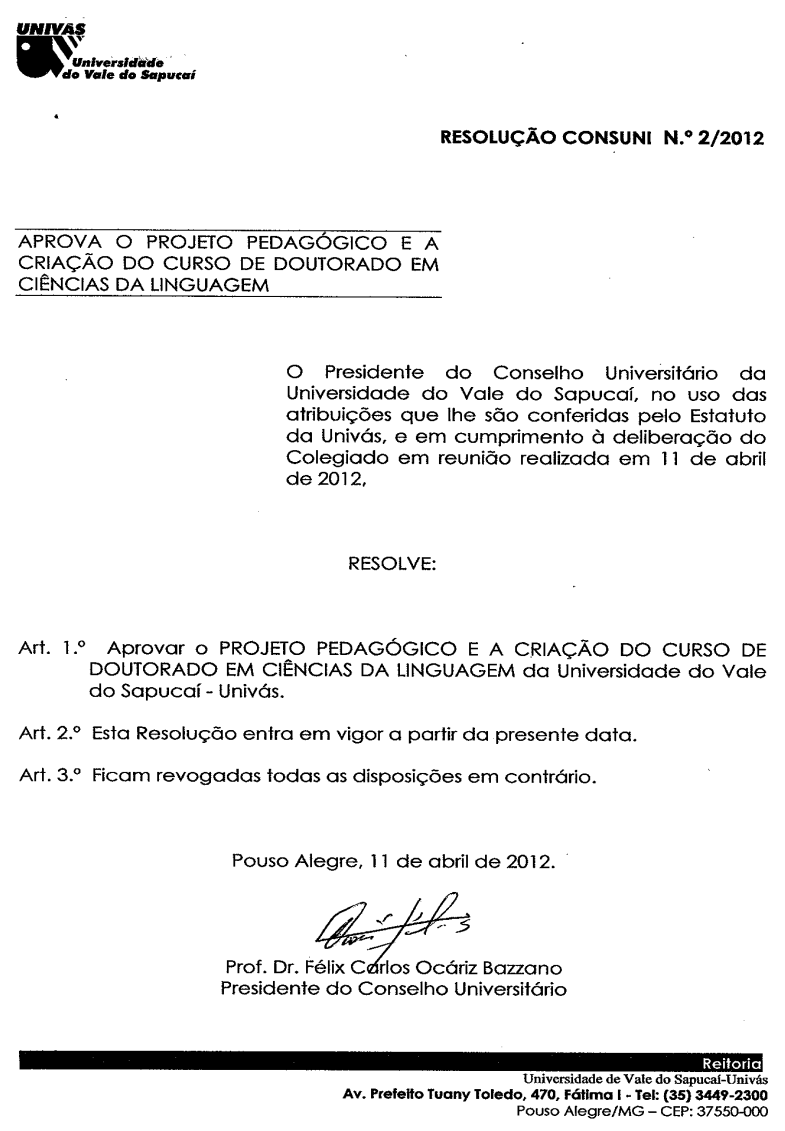

Na UNIVÁS, e na região sul de Minas, a cada ano, centenas de alunos se formam em áreas em que se insere o estudo da linguagem. Com o funcionamento do Doutorado em Ciências da Linguagem, eles terão a oportunidade de uma formação continuada e de uma formação mais avançada como pesquisador. Este doutorado atenderá, portanto, um grande número de profissionais que precisam dessa formação a fim de incrementar, de um lado, a produção de conhecimento nos diversos domínios das ciências humanas e sociais, tendo a questão da linguagem como elemento central e articulador, e, de outro, o ensino, especialmente na região sul mineira ${ }^{17}$.

De fato, o potencial cientifico da região vinha se desenvolvendo desde 2002. Assim, passados mais de 10 anos da implementação da primeira versão deste projeto intelectual de formação acadêmico-científica de excelência, a proposta de ampliação do curso de Mestrado em Ciências da Linguagem para um Programa de Pós-Graduação em Ciências da Linguagem com Mestrado e Doutorado, além de atender à solicitação de um público alvo eclético, também atendia às necessidades da própria instituição que, como vimos anteriormente, precisava se readequar às regras do Ministério da Educação para a manutenção do status de Universidade.

Eni P. Orlandi atenta a este cenário heterogêneo organizou, junto a uma equipe dinâmica e competente ${ }^{18}$, que já vinha se formando desde o início do curso, um projeto

${ }^{16}$ CONSELHO UNIVERSITÁRIO (CONSUNI). Resolução n. 2/2012. In PRÓ-REITORIA DE PESQUISA E PÓSGRADUAÇÃO. Arquivo Institucional. Universidade do Vale do Sapucaí. Pouso Alegre, 2012.

${ }^{17}$ Recorte retirado da Proposta de Doutorado enviada à CAPES em 2013, conforme arquivo institucional. In: PRÓREITORIA DE PESQUISA E PÓS-GRADUAÇÃO. Arquivo Institucional. Universidade do Vale do Sapucaí. Pouso Alegre, 2013.

${ }^{18}$ Equipe constituída por pesquisadores de vários domínios das Ciências da Linguagem, como linguística, análise de discurso, semântica da enunciação e semântica formal, pragmática, linguística aplicada, psicolinguística, semiótica, 
de Doutorado ainda mais inovador do que aquele de Mestrado apresentado à CAPES em 2009. Mantendo sua filiação à área de concentração "Linguagem e Sociedade", o Projeto de Doutorado em Ciências da Linguagem da UNIVÁS foi desenvolvido e articulado em torno de três linhas de pesquisa: além de Análise de Discurso e Língua e Ensino, que faziam parte do projeto original de Mestrado (2009), inseriu-se uma terceira linha, a saber, Linguagem, Conhecimento e suas Tecnologias. Sendo propostas de modo que se aglutinariam em torno de um ponto comum e se especificariam em sua diversidade, as três linhas constituiriam assim o eixo central do Doutorado. Idealizado para reunir pesquisas empreendidas a partir de diferentes perspectivas ou áreas do conhecimento (Letras, Artes, Ciências Contábeis, Administração, Comunicação, Direito, Psicologia, Educação, Enfermagem, Medicina, Fonoaudiologia, História, Biologia, etc.) articuladas à área de concentração, o Projeto Político Pedagógico do curso de Doutorado enviado à CAPES destacava-se justamente por ter a área de concentração como ponto norteador às três linhas de pesquisa. Esta especificidade pode ser considerada também como a grande inovação deste projeto, pois as três linhas tinham

\begin{abstract}
como base a análise da linguagem funcionando na sociedade e na história, análise que, como sabemos, pressupõe a linguística, mas considera a língua apenas relativamente autônoma na medida em que, para significar, a língua se inscreve na história e, desse modo, trata da relação da língua com os sujeitos e a situação, e não apenas como gramática. Essa forma de pensar a língua e, de forma mais abrangente, a linguagem, articulada às práticas sociais e históricas, pode ser muito fecunda tanto para profissionais que, conhecendo a linguagem em seu modo de produzir sentidos, assim como as novas tecnologias, levam esse conhecimento para a melhor compreensão de seus objetos, como para aqueles que trabalham o próprio ensino da língua e que se beneficiam assim de uma nova (p. 10) ${ }^{19}$.
\end{abstract}

A proposta do curso de Doutorado foi efetivamente enviada à CAPES em meados de 2013. Naquele mesmo ano, recebeu-se a recomendação do Conselho Técnico-Científico da Educação Superior $(\mathrm{CTC})^{20}$ para instalação do curso de Doutorado que passou a funcionar a partir de 2014. Paralelamente ao envio dessa proposta, o Mestrado passava pela sua primeira avaliação trienal em que obteve nota 4. O resultado desses dois processos, a recomendação do curso de Doutorado e a avaliação (nota 4) do curso de Mestrado, certamente, validaram e certificaram a excelência deste percurso (ainda inicial, pode-se dizer) da pós-graduação da UNIVÁS. E, além disso, esse reconhecimento positivo ao trabalho que vinha sendo desenvolvido no sul de Minas é, antes de tudo, a legitimação e a homologação do projeto intelectual de Eni P. Orlandi na institucionalização de um Programa de Pós-graduação em Ciências da Linguagem. Vale reafirmar a importância que tem sido dada, sistematicamente, neste Programa, à formação do professor pesquisador e ao conhecimento da linguagem para especialistas de outras áreas, como forma de expandir e aperfeiçoar o conhecimento das ciências da linguagem, e avalizar outras formas de conhecimento tendo como ferramenta o melhor conhecimento da linguagem, ou das linguagens.

fonologia, fonoaudiologia, tecnologias da linguagem, ensino de língua materna e línguas estrangeiras, e outros. Os docentes da equipe fizeram seus mestrados, doutorados, e pós-doutorados em importantes instituições brasileiras ou estrangeiras, o que potencializa a prática consequente da multidisciplinaridade.

19 PROGRAMA DE PÓS-GRADUAÇÃO EM CIÊNCIAS DA LINGUAGEM. Projeto Político Pedagógico. PróReitoria de Pesquisa e Pós-Graduação. Universidade do Vale do Sapucaí. Pouso Alegre, 2014. In: https://www.cienciasdalinguagem.net/projeto-pedaggico. Acesso em 17 set. 2017.

${ }^{20}$ Conforme Ofício No 170-30/2013/CTC/CAA II/CGAA/DAV, de 17 de setembro de 2013. 
Conforme é possível observar, a força do ferreiro e a habilidade da língua (intérprete) foram sempre necessárias para o processo de criação, de execução e de institucionalização do projeto pioneiro de Orlandi na UNIVÁS. No início dessa reflexão, falou-se do trabalho incansável de Eni P. Orlandi na implementação e na coordenação do hoje se chama Programa de Pós-Graduação em Ciências da Linguagem.

Se hoje temos um Programa de Pós-Graduação na UNIVÁS, com mestrado e doutorado, é porque Eni P. Orlandi sempre esteve comprometida com a realização deste projeto. A instituição certamente cuidou para que as condições estruturais fossem favoráveis à realização desse feito. Mas, obviamente, sem a orientação, sem o comprometimento, sem o olhar criterioso e vanguardista de Eni P. Orlandi, este projeto não teria a visibilidade e a força que tem hoje.

Em outras palavras, podemos dizer que o percurso de Eni P. Orlandi na UNIVÁS nos mostrou na práxis, no real do trabalho institucional, que fazer ciência é antes de tudo um gesto político que produz impactos sociais inimagináveis, afinal "todo dizer é um gesto político, porque toda significação tem uma direção, divide. (...) Falar em ciência, então, já que ciência, tecnologia e administração (governo) se sobredeterminam, necessariamente, é um gesto político por excelência com consequências sociais muito relevantes" (Orlandi, 2004, p. 129). De fato, os dizeres e os gestos acadêmico-científicos de Eni P. Orlandi instituíram e institucionalizaram a pesquisa (e a pós-graduação) na UNIVÁS e no sul de Minas. Entre "o já-dito e o a-sedizer" (Orlandi, 1983, p.9.), Eni P. Orlandi faz as Ciências da Linguagem.

\section{REFERÊNCIAS}

CONSELHO UNIVERSITÁRIO (CONSUNI). Resolução n. 9/2009. In PRÓREITORIA DE PESQUISA E PÓS-GRADUAÇÃO. Arquivo Institucional. Universidade do Vale do Sapucaí. Pouso Alegre, 2009.

Resolução n. 2/2012. In PRÓ-REITORIA DE PESQUISA E PÓSGRADUAÇÃO. Arquivo Institucional. Universidade do Vale do Sapucaí. Pouso Alegre, 2012.

MINISTERIO DA EDUCAÇÃO. < http://portal.mec.gov.br/component/content/article?id=15924:exigencia-de-doutoradostorna-mais-rigidas-regras-para-as-universidades $>$. Acesso em 02 set.2017.

ORLANDI, E. P. A linguagem e seu funcionamento. As formas do discurso. São Paulo: Brasiliense, 1983.

Cidade dos Sentidos. Campinas: Pontes, 2004.

Entrevista com Eni P. Orlandi. In MASSMANN, D.; BARROS, R.; DIAS, J.; SOARES, A. C. Curta-metragem "Programa de Pós-Graduação em Ciências da Linguagem (PPGCL) 15 anos". Pouso Alegre: Editora da UNIVAS, 2017. (no prelo)

PROGRAMA DE PÓS-GRADUAÇÃO EM CIÊNCIAS DA LINGUAGEM. Projeto Político Pedagógico. Pró-Reitoria de Pesquisa e Pós-Graduação. Universidade do Vale do Sapucaí. Pouso Alegre, 2014. In: https://www.cienciasdalinguagem.net/projetopedaggico. Acesso em 17 set. 2017.

. Proposta de curso de Doutorado Ciências da Linguagem. In: PRÓ-REITORIA DE PESQUISA E PÓS-GRADUAÇÃO. Arquivo Institucional. Universidade do Vale do Sapucaí. Pouso Alegre, 2013. 
Arquivo do PPGCL. In PRÓ-REITORIA DE PESQUISA E PÓSGRADUAÇÃO. Arquivo Institucional. Universidade do Vale do Sapucaí. Pouso Alegre, 2002-2009.

Arquivo do PPGCL. In PRÓ-REITORIA DE PESQUISA E PÓSGRADUAÇÃO. Arquivo Institucional. Universidade do Vale do Sapucaí. Pouso Alegre, 2009-2014.

Recebido em: setembro de 2017.

Aprovado em: novembro de 2017.

\section{Como citar este trabalho:}

MASSMANN, D. Entre "o já-dito e o a-se-dizer": o Programa de Pós-Graduação em Ciências das Linguagem. Traços de linguagem, v. 2, n. 1, p. 62-75, 2018. 